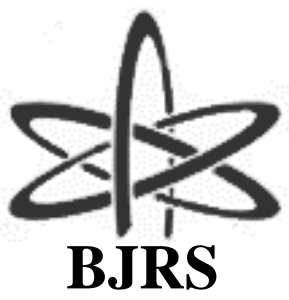

BRAZILIAN JOURNAL

$\mathrm{OF}$

RADIATION SCIENCES

08-03B (2021) 01-17

\title{
Numerical Simulation Study on the Air/Water Counter- current Flow Limitation in Nuclear Reactors
}

\author{
Y. Morghi ; A. Z. Mesquita ${ }^{\text {a }}$ J. A. Puente ; A. R. Baliza ${ }^{\text {c }}$ \\ ${ }^{a}$ Centro de Desenvolvimento da Tecnologia Nuclear (CDTN/CNEN) Campus da UFMG - Pampulha, Belo Horizonte, \\ 31270-901, MG, Brasil \\ ${ }^{b}$ Centro Federal de Educaçao Tecnologica Celso Suckowda Fonseca, Cefet, Campus Angra dos Reis-RJl \\ ${ }^{c}$ Eletrobras Eletronuclear Angra dos Reis - RJ, Rodovia Procurador Haroldo Fernandes Duarte - BR101/RJ,S/N km \\ 521,56, Itaorna $-R J$ \\ ssfmorghi@gmail.com
}

\begin{abstract}
After a loss-of-coolant accident (LOCA) in a Pressurized Water Reactor (PWR), the temperature of the fuel elements cladding increases dramatically due to the heat produced by the fission products decay, which is not adequately removed by the vapor contained in the core. In order to avoid this sharp rise in temperature and consequent melting of the core, the Emergency Core Cooling System is activated. This system initially injects borated water from accumulator tanks of the reactor through the inlet pipe (cold leg) and the outlet pipe (hot leg), or through the cold leg only, depending on the plant manufacturer. Some manufacturers add to this, direct injection into the upper plenum of the reactor. The penetration of water into the reactor core is a complex thermofluidodynamic process because it involves the mixing of water with the vapor contained in the reactor, added to that generated in the contact of the water with the still hot surfaces in various geometries. In some critical locations, the vapor flowing in the opposite direction of the water can control the penetration of this into the core. This phenomenon is known as Countercurrent Flow Limitation (CCFL) or Flooding, and it are characterized by the control that a gas exerts in the liquid flow in the opposite direction. This work presents a proposal to use a CFD to simulate the CCFL phenomenon. Numerical computing can provide important information and data that is difficult or expensive to measure or test experimentally. Given the importance of computational science today, it can be considered a third and independent branch of science on an equal footing with the theoretical and experimental sciences.
\end{abstract}


Keywords: Countercurrent Fow Limitation (CCFL), Computational fluid dynamics, LOCA, PWR.

\section{INTRODUCTION}

Countercurrent flows of water and air are of great importance in the field of safety analysis of nuclear reactors. The possible occurrence of CCFL in the hot-leg of a PWR during LOCA or SBLOCA accidents is of special interest for nuclear safety research. The countercurrent flow limitation (CCFL), or flooding, represents a condition in which a gas flow establishes a control on the liquid flow in the opposite direction. The CCFL was extensively studied over the last decades. Various experimental facilities were built to study this phenomenon. This experimental facility has the same characteristics of a PWR hot leg.

Computational Fluid Dynamics (CFD) is proved to be one of the vital parts of the computer aided engineering (CAE) tools, and it has been extensively used for various purposes. It approach to model fluid flow phenomena allows engineers and technical analysts to have a powerful fluid simulation on their desktop.

\section{MATERIALS AND METHODS}

The Countercurrent Flow Limitation (CCFL) occurs when the liquid and gas are flowing in opposite directions. A stratified countercurrent flow gas and liquid is only stable for a certain range of mass flow rates. If the gas mass flow rate increases too much, the liquid flow is stopped and then it will be carried over by the gas and partially or totally flows in the opposite direction [1]. Onset of CCFL corresponds to the limiting condition where the flow rates of neither the gas nor the liquid can be further increased without changing the flow pattern and limiting the liquid flow rate, or it is the limiting point of stability of the countercurrent flow indicated by the maximum air mass flow rate at which the down flowing water mass flow rate is equal to the inlet water mass flow rate. This 
limiting condition - known also as onset of flooding - can happen in vertical or horizontal geometry $[1],[2],[3]$.

Countercurrent flows of water and steam are of great importance in the field of safety analysis of nuclear reactors. CCFL can occur in the hot-leg of a pressurized water reactor PWR during a loss of coolant accident, LOCA or SBLOCA and in the event of loss of residual removal system (loss of RHR) [4], [5].

In hot-leg geometry a smooth stratified establishes at low liquid and gas superficial velocities. As the gas velocity increases, disturbances start to appear at the interface. Small waves initiate and grow. Instabilities, hydraulic jump, wave growth, droplets entrainment, and chaotic interface movement appearance and development leads eventually to CCFL occurrence. Figure 1 shows the appearance of these disturbances during a CCFL experiment [1].

Figure 1: Appearance of disturbances during a CCFL experiment [1].

\begin{tabular}{|c|c|}
\hline & (b) hydraulic jump at the bend \\
\hline (a) hydraulic jump near the water exit & (d) droplets \\
\hline (c) wave near the bend & (dow
\end{tabular}

To investigate CCFL phenomenon, many experimental systems were built, as shown in the schematic diagram (Fig. 2), and the photo of the water-air circuit built in the CDTN (Fig. 3). Water and air, at room temperature and atmospheric pressure, are the working fluids. The experimental investigations of CCFL use similar experimental systems changing the geometrical characteristics and 
velocity of gas and water. These experimental built has the same characteristics of a PWR hot leg [2]. In a typical experiment, the water from the reservoir is pumped to the upper tank (UT) from where it precipitates by gravity through the test section to the lower tank (LT). The air injected in the lower tank flows in countercurrent through the test section to the upper tank and after that is released to the atmosphere.

Figure 2: Experimental diagram [2].

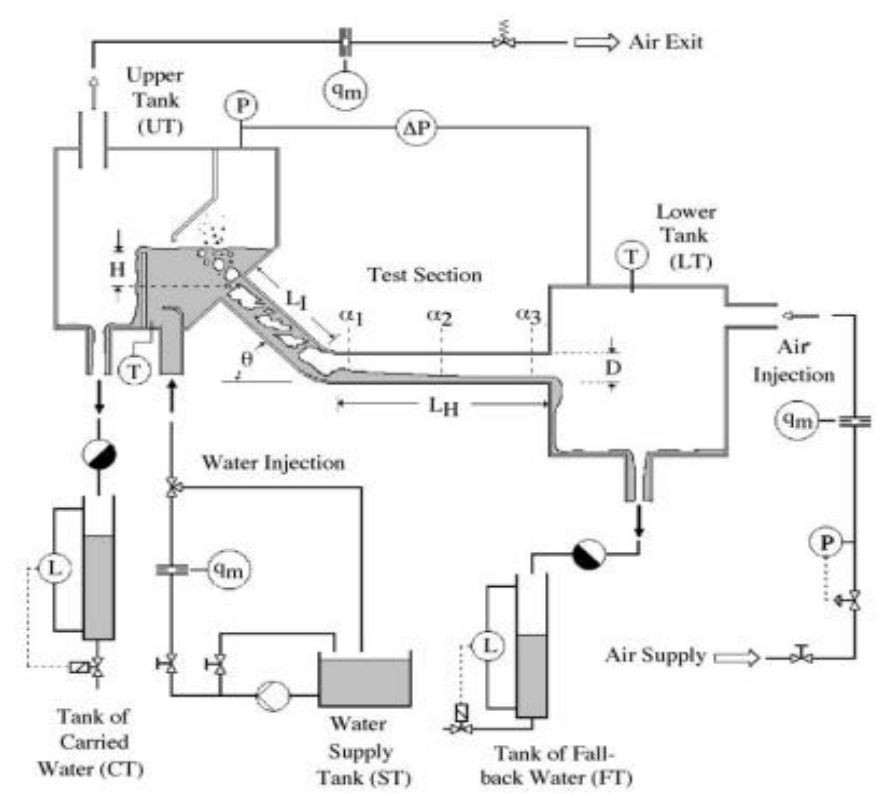

Figure 3: Hot leg model at water-air circuit in CDTN.

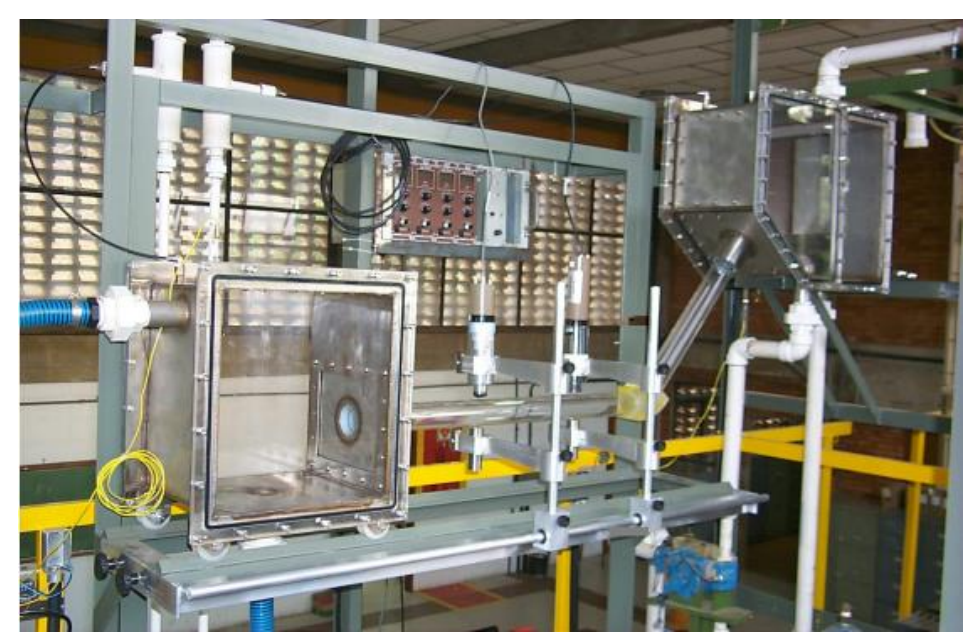


In 2005 [2], it was performed several experiments in hot-leg geometry and with different geometrical characteristics of the bend and rise exist to the upper tank. these experiments includes various water and air flow rates for each test section configuration (LH, LI, D, $\theta, \mathrm{H})$.

The results were:

a) The onset of flooding does not depend only on the dimensional characteristics of the test section but also on the injected water flow rate. Depending on this flow rate different mechanisms lead to onset of flooding, which can occur in different positions of the test section: at the horizontal pipe, close to the bend, for low flow rate, due to the formation of a hydraulic jump; at the lower end, for intermediate flow rates, with the formation of a slug in this position, and at the upper extremity, due to the area reduction to the air flow with higher injected flow rates.

b) Figure 4: Onset of flooding as a function of the water injection rates [2].

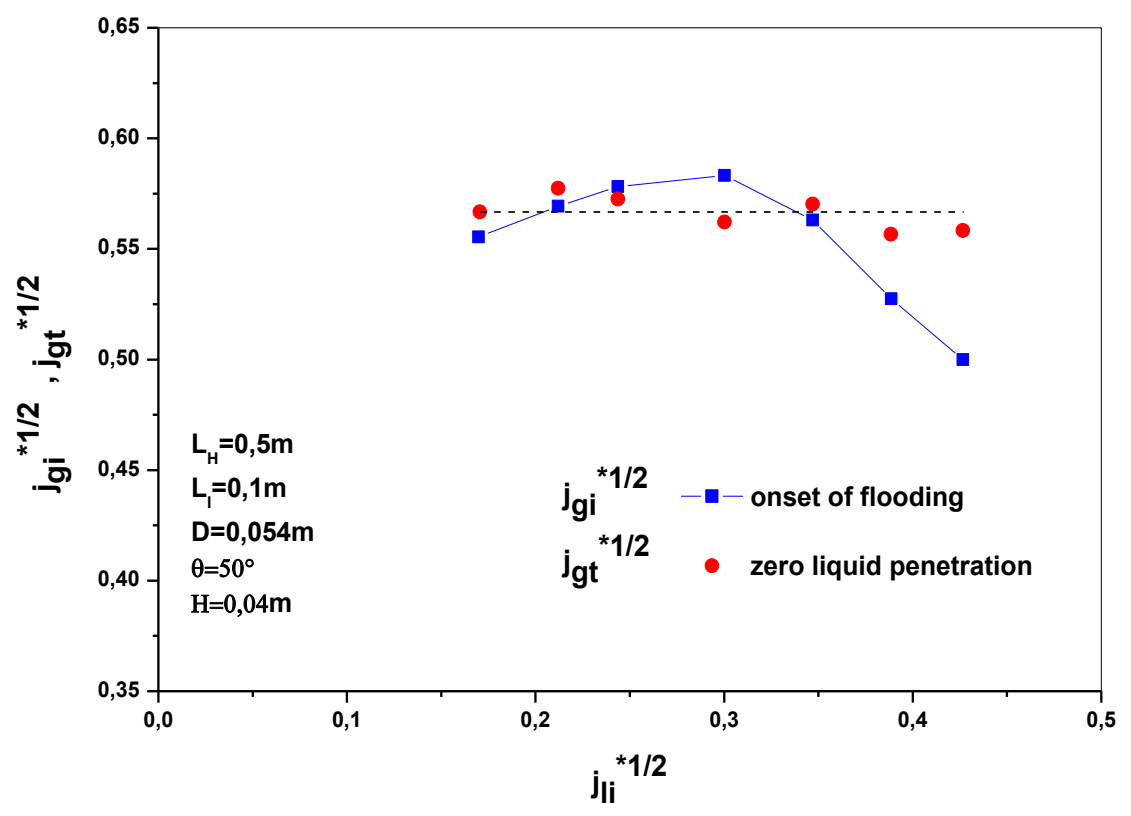

b) The limitation phase with partial delivery, however, does not depend on the injected water flow rate and is only influenced by the dimensional characteristics of the test section. From the analysis of the influences of the geometric characteristics of the test section on the flooding curve with partial delivery, the following conclusions were obtained: for a fixed air velocity, an increase in 
the horizontal length or in the inclined length of the flow channel provokes an increase in the water carried out by the air, while an increase of the diameter leads to a decrease of the carried water. Little difference was observed among the curves with inclinations lower than $90^{\circ}$. For this inclination, however, the carried water tends to be larger than in others angles for a fixed air velocity.

Figure 5: Effect of the inclined length of the test section on the partial delivery [2].

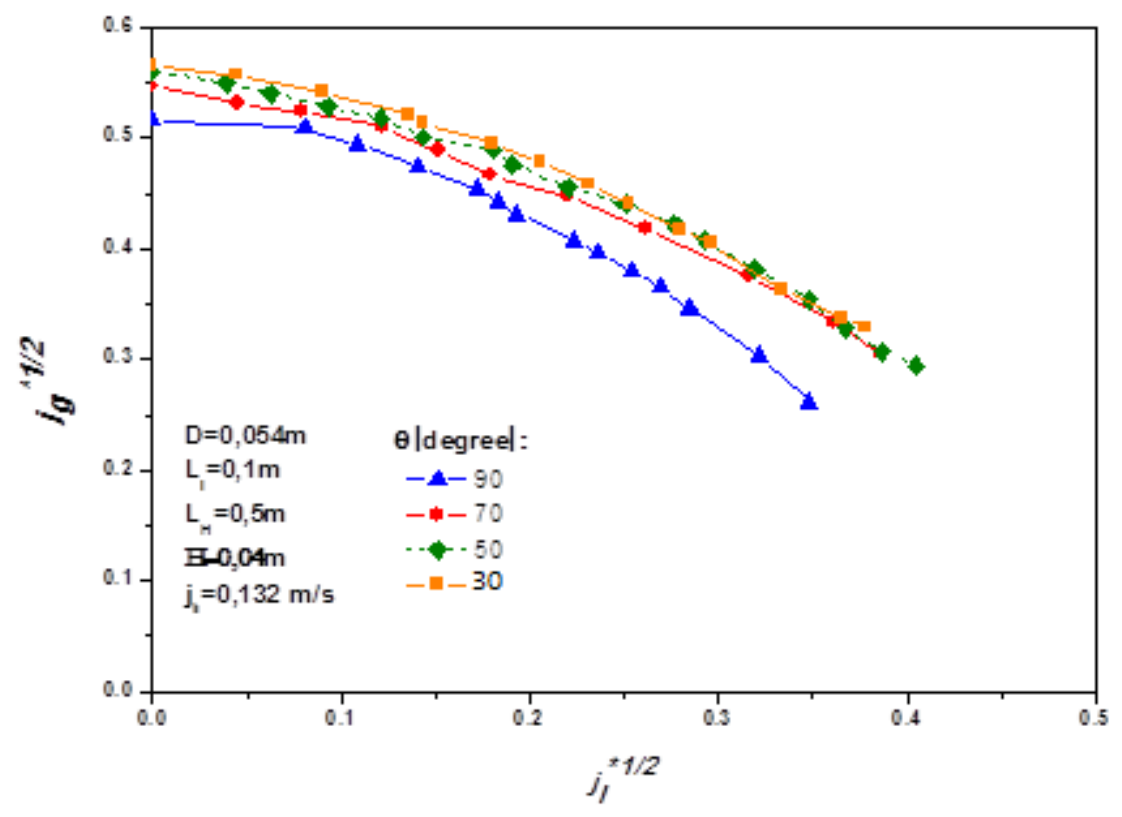

\subsection{COMPUTATIONAL FLUID DYNAMICS (CFD)}

Computational Fluid Dynamics (CFD) since actual measurements of gas-liquid flow conditions in real nuclear facility experiment is too expensive, not free of hazards and sometimes, difficult or even impossible to measure the relevant data. Numerical simulation by CFD codes can provide more economical, time efficient alternative that can also yield the values of a larger quantity of flow defining variables. It is clear, however, that for CFD codes to "replace" experiments, especially when nuclear safety issues are at stake, will require extensive, thorough and rigorous validation and assessment of their integral results and that of the modes implemented in them to address the different physical processes of interest. Computational fluid dynamics (CFD), is a branch of fluid 
mechanics that uses numerical analysis and algorithms to solve and analyze problems that involve fluid flows - simulate the interaction of liquids and gases with boundary conditions defined. To obtain final validation of the results for a full-scale simulation, it is important to perform experimental validation, where the results of experimental simulation are compared with CFD result [8], [9], [10]..

How described before, several experiments have been conducted to investigate the countercurrent flow limitation (CCFL) in the hot leg, and empirical correlations for CCFL have been proposed using the Wallis parameters. In order to evaluate these effects effectively, numerical simulation using CFD (computational fluid dynamics) software can be used [11].

One basic procedure/methodology can be described to use CFD:

- The geometry of the problem is defined.

- The volume occupied by the fluid is divided into discrete cells.

- The physical modeling is defined.

- Boundary conditions are defined. For transient problems, the initial conditions are also defined.

- The domain is discretized into a series of grid points.

- The simulation is started and the equations are solved iteratively as a steady-state or transient.

- Finally a postprocessor is used for the analysis and visualization of the resulting solution.

The introducing of CFD method on the countercurrent flow in a model of PWR hot-leg includes the investigation of CCFL mechanisms, heat transfer effects, flow patterns, hysteresis behavior, and the extension of the obtained flow behavior from small scale to full reactor scale. There is a vast number of CFD options for the engineering community. In this work, the numerical simulations were performed in Ansys Fluent and it was used the Volume of Fluid (VOF) method. 


\subsection{THE VOF METHOD}

the volume of fluid (VOF) method belongs to the Euler-Euler framework where all phases are treated as continuous, but in contrary to the previous presented models the VOF model does not allow the phases to be interpenetrating. The equations solved in the VOF method are shown below.

$$
\frac{\partial \rho_{m}}{\partial \mathrm{t}}+\nabla \cdot\left(\rho_{m} \overline{\boldsymbol{u}}\right)+\nabla \cdot\left[u_{r} \rho_{m}\left(1-\rho_{m}\right)\right]=0
$$

$$
\frac{\partial \alpha}{\partial \mathrm{t}}+\nabla \cdot(\alpha \mathrm{u})=0
$$

$\rho_{m}=\Sigma \alpha_{k} \rho_{k}$ The subscript $\mathrm{m}$ refers to mixture properties.

As the focus of the VOF method is to track the interface between two or more phases it is suitable for flows with sharp interfaces, such as slug, stratified or free-surface flows.

The VOF model can model two or more immiscible fluids by solving a single set of momentum equations and tracking the volume fraction of each of the fluids throughout the domain. Typical applications include the prediction of jet breakup, the motion of large bubbles in a liquid, the motion of liquid after a dam break, and the steady or transient tracking of any liquid-gas interface [11].

The VOF formulation in Fluent is generally used to compute a time-dependent solution, but for problems in which you are concerned only with a steady-state solution, it is possible to perform a steady-state calculation. A steady-state VOF calculation is sensible only when your solution is independent of the initial conditions and there are distinct inflow boundaries for the individual phases. For example, since the shape of the free surface inside a rotating cup depends on the initial level of the fluid, such a problem must be solved using the time-dependent formulation. On the other hand, 
the flow of water in a channel with a region of air on top and a separate air inlet can be solved with the steady-state formulation [11].

The VOF formulation relies on the fact that two or more fluids (or phases) are not interpenetrating. For each additional phase that you add to your model, a variable is introduced: the volume fraction of the phase in the computational cell. In each control volume, the volume fractions of all phases sum to unity. The fields for all variables and properties are shared by the phases and represent volume-averaged values, as long as the volume fraction of each of the phases is known at each location. Thus the variables and properties in any given cell are either purely representative of one of the phases, or representative of a mixture of the phases, depending upon the volume fraction values. In other words, if the qth fluid's volume fraction in the cell is denoted as $\alpha \mathrm{q}$, then the following three conditions are possible [11]:

$\alpha_{q}=0$ : The cell is empty (of the $q^{\text {th }}$ fluid).

$\alpha_{q}=1$ : The cell is full (of the $q^{\text {th }}$ fluid).

$0<\alpha_{q}<1$ : The cell contains the interface between the $q^{\text {th }}$ fluid and one or more other fluids.

Based on the local value of $\alpha_{\mathrm{q}}$, the appropriate properties and variables will be assigned to each control volume within the domain.

\subsection{VOLUME FRACTION}

The tracking of the interface(s) between the phases is accomplished by the solution of a continuity equation for the volume fraction of one (or more) of the phases. For the $q^{\text {th }}$ phase, this equation has the following form:

$$
\frac{1}{p_{q}}\left[\frac{\partial}{\partial t}\left(\alpha_{q} \rho_{q}+\nabla \cdot\left(\alpha_{q} \rho_{q} \overrightarrow{v_{q}}\right)=S_{\alpha_{q}}+\sum_{p=1}^{n}\left(\dot{m}_{p q-} \dot{m}_{q p}\right)\right]\right.
$$


Where $\dot{m}_{q p}$ is the mass transfer from phase $q$ to phase $p$ and $\dot{m}_{p q}$ is the mass transfer from phase $p$ to phase $q$. By default, the source term on the right-hand side of Equation $4, S_{\alpha_{q}}$, is zero, but you can specify a constant or user-defined mass source for each phase.

The volume fraction equation will not be solved for the primary phase; the primary-phase volume fraction will be computed based on the following constraint:

$$
\sum_{q=1}^{n} \propto_{q}=1
$$

The volume fraction equation may be solved either through implicit or explicit time discretization.

\section{RESULTS AND DISCUSSION}

In the present simulation, the flow was treated as transient. The problem is three dimensional (3-D), consequently, it has to be solved by applying Computational fluid Dynamics (CFD) methods. The geometry, mesh and numerical simulations were performed using Ansys Fluent, and the method implemented were the VOF. The simulation parameters are according to Figure 2 and Table 1.

Table 1: Simulation parameters (see Figure 2)

\begin{tabular}{|c|c|}
\hline Parameter & Value \\
\hline $\mathrm{D}(\mathrm{m})$ & 0.054 \\
\hline$\theta$ & 50.00 \\
\hline $\mathrm{H}(\mathrm{m})$ & 0.085 \\
\hline $\mathrm{L}_{H}(\mathrm{~m})$ & 0.100 \\
\hline $\mathrm{L}_{1}(\mathrm{~m})$ & 0.500 \\
\hline $\mathrm{V}_{\text {liquid }}(\mathrm{m} / \mathrm{s})$ & 0.022 \\
\hline $\mathrm{V}_{\text {gas }}(\mathrm{m} / \mathrm{s})$ & 0.06 \\
\hline
\end{tabular}


First, the geometry were built, after the mesh were created automatically by the Fluent, so the mesh is the standard of the software, that is no changes were implemented. Figure 6 shows the comparison between the appearance of the mesh in literature and for this work. A good agreement can be observed in the appearance of the mesh generation between the literature [11] and the present work.

Figure 6: Computational grids (a) literature [12] (b) present work.

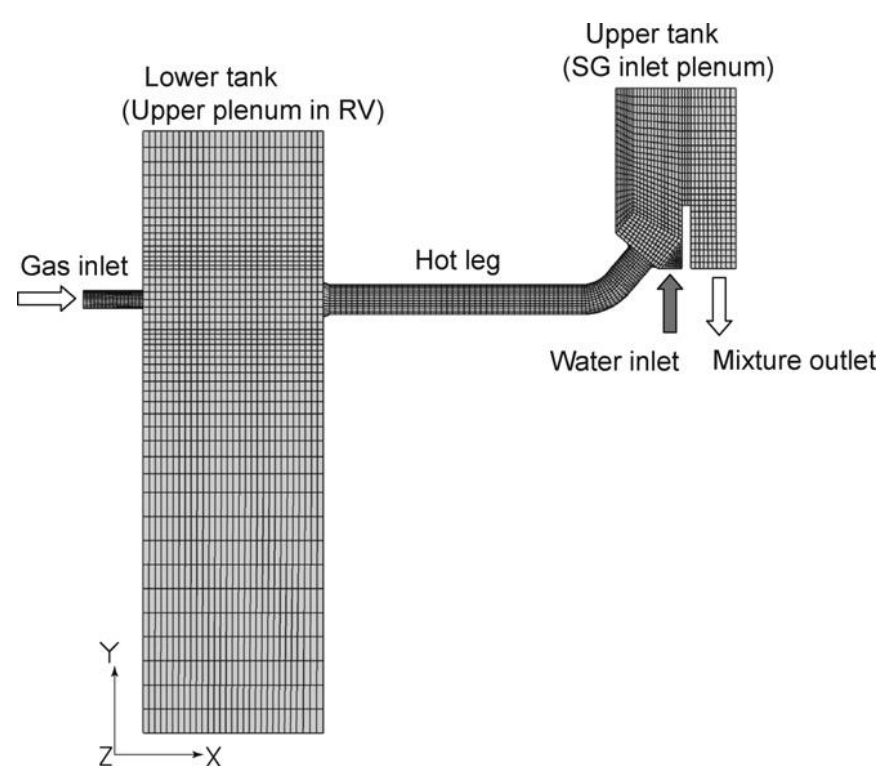

(a)

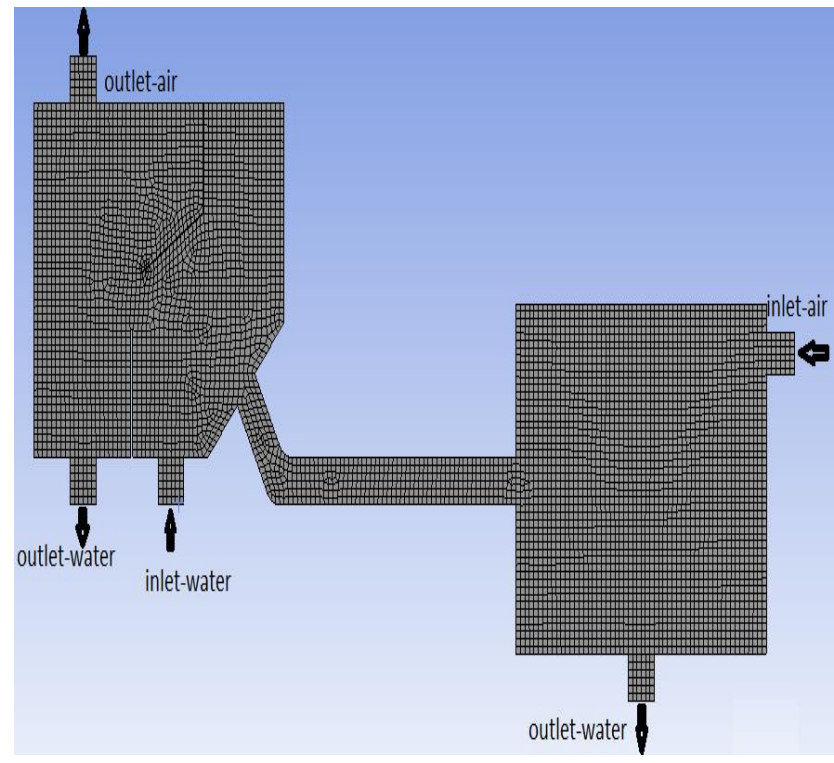

(b)

Figure 7: The full geometry in Ansys Fluent (after mesh creation).
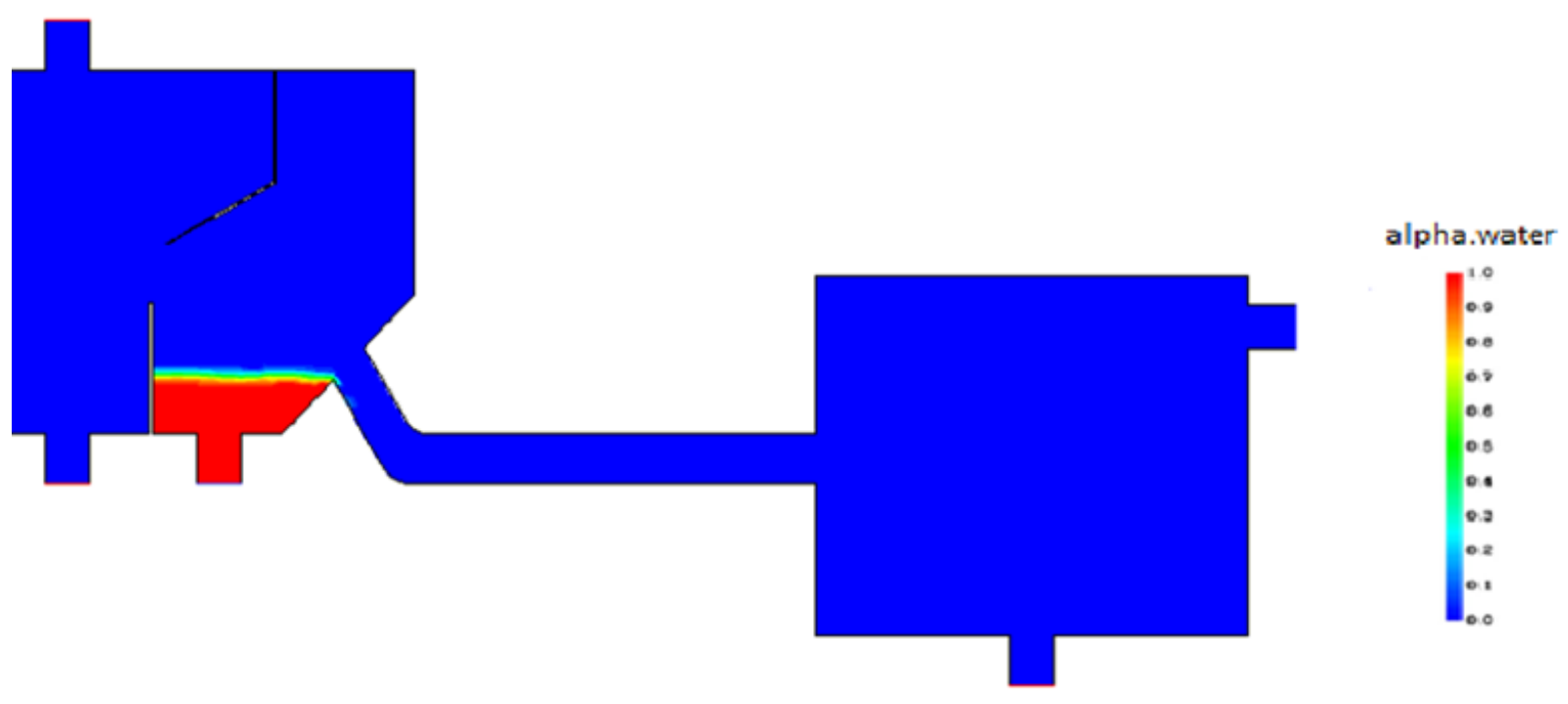
The fluid in the system are water and air, so, the Fluent label vary from blue to red $\left(0 \leq \alpha_{\text {water }} \leq 1\right)$, when $\alpha_{\text {wate }} r=1$ (completely water), the Fluent label is red and when $\alpha_{\text {water }}=0$, the Fluent label is blue and it means that there is $100 \%$ of air in this place of geometry $\left(\alpha_{\text {air }}=1\right)$.

To start the simulation, it is necessary to introduce water in the inlet water, as shown in figure 8 . The arrow shows the inlet and outlet of water.

Figure 8: Starting the water inlet - velocity $0.022 \mathrm{~m} / \mathrm{s}$.

\section{alpha. water}

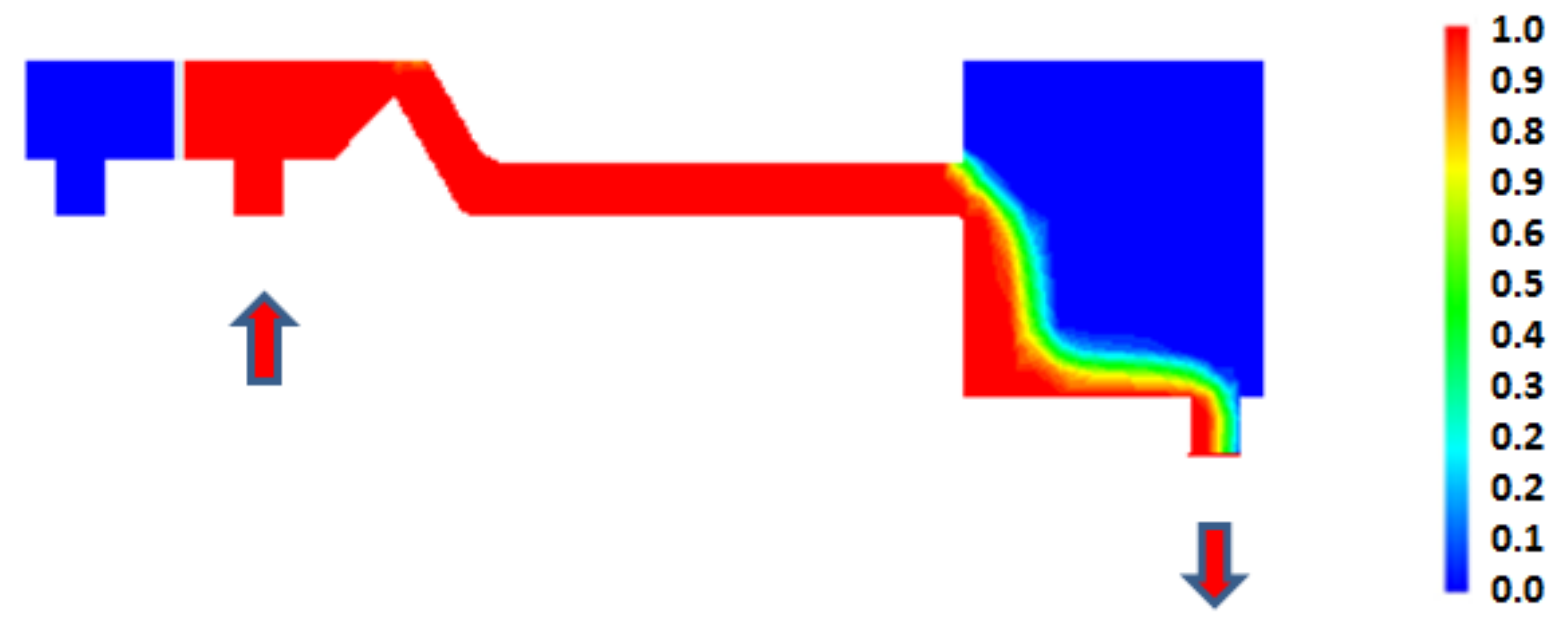

After the simulation starts the volumetric fraction of water and air vary, and the same disturbances observed in the literature [1] start to appear at the interface as shown in Figure 9. Comparing Figure 1 and Figure 9, the same instabilities, hydraulic jump, and chaotic interface movement appearance during a CCFL are observed, but it was not observed deflooding. 
Figura 9: Interface water/air during the time - velocity of water $0.022 \mathrm{~m} / \mathrm{s}$.

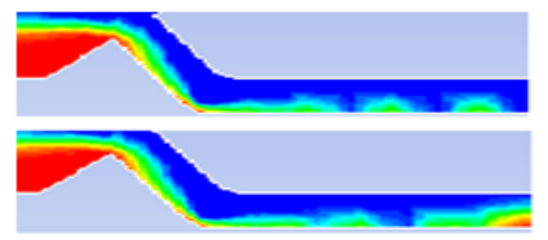

alpha. water

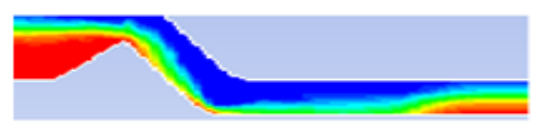

1.0

0.9

0.8

0.9

0.6

0.5

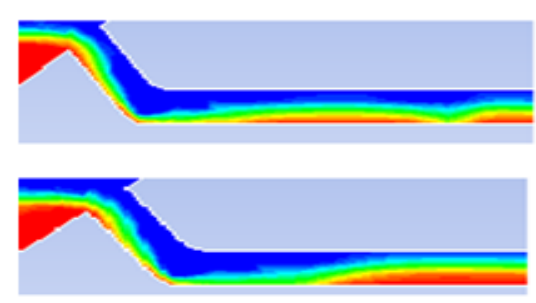

0.4

0.3

0.2

0.2

0.1

Figure 10 shows a hydraulic jump near the bend. The hydraulic jump is important because it shows the beginning of CCFL.

Figura 10: Hdraulic jump - velocity $0.022 \mathrm{~m} / \mathrm{s}$.

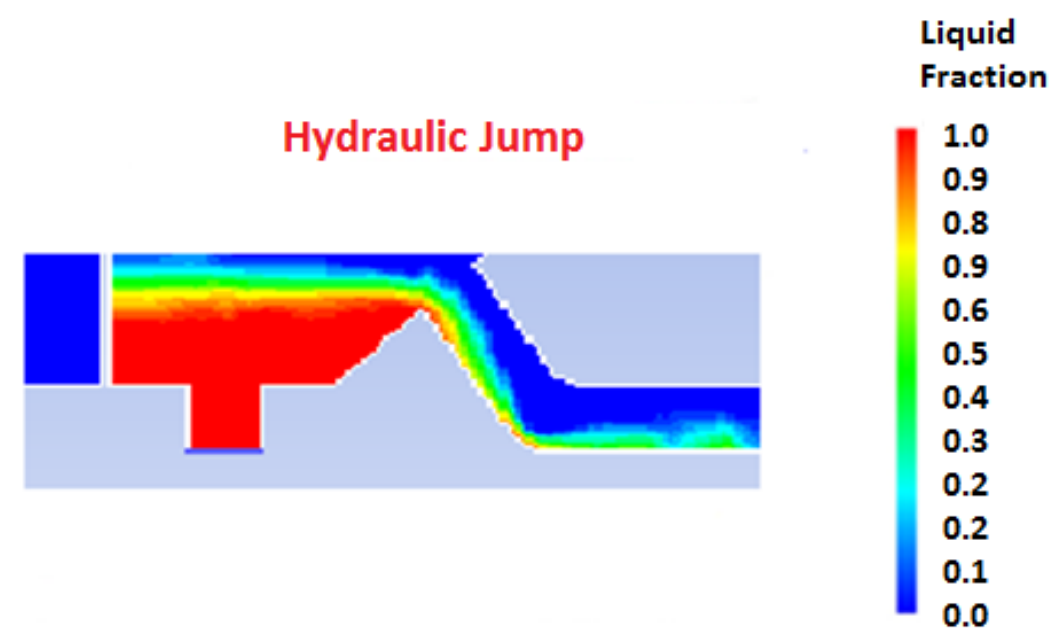

During the simulation it is possible to measure the pressure variation and the turbulance kinetic energy throughout the test section, as shown in Fig. 11 and Fig. 12 respectivily, it was not possible to obtain the flooding and deflooding curves, using the parameters of Table 1. 
Figure 11: Pressure variation throughout the test section.

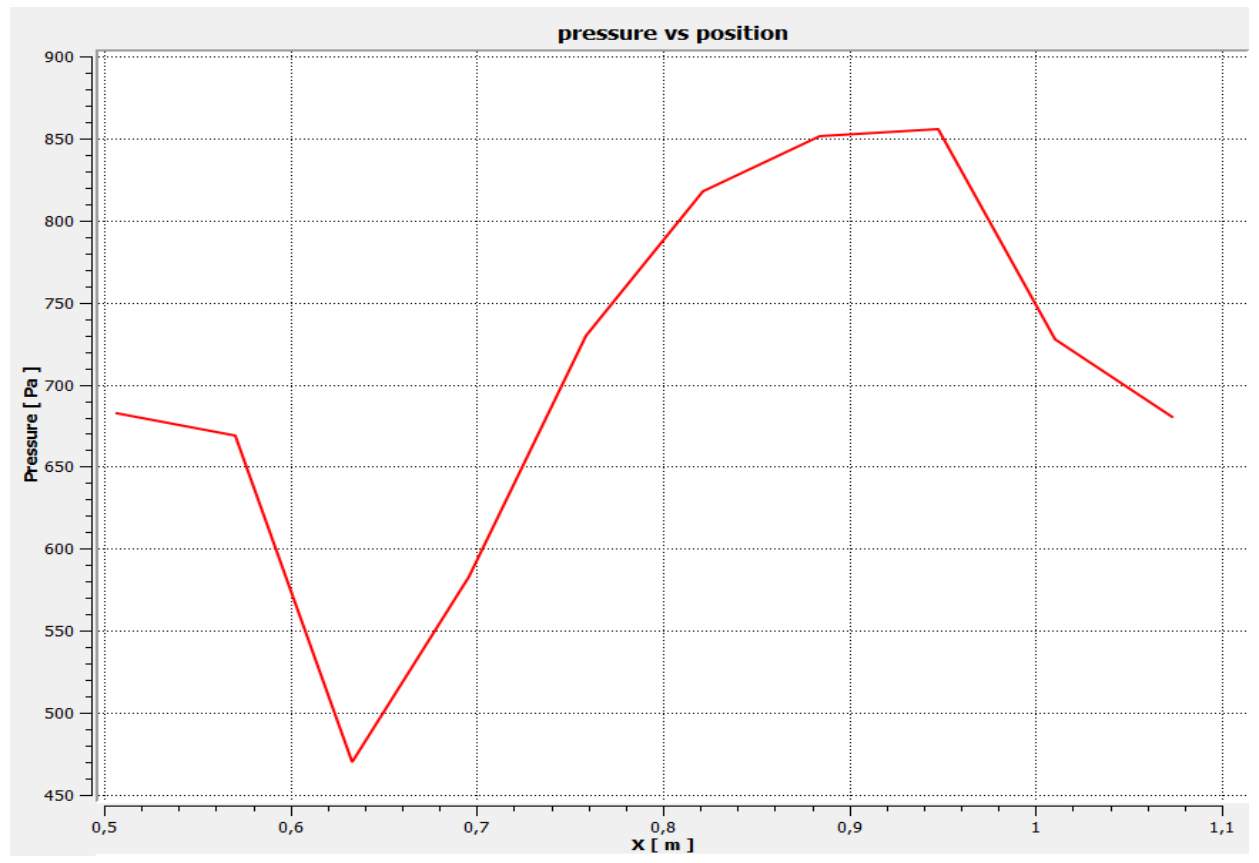

Figure 12: Turbulence kinetic energy variation throughout the test section.

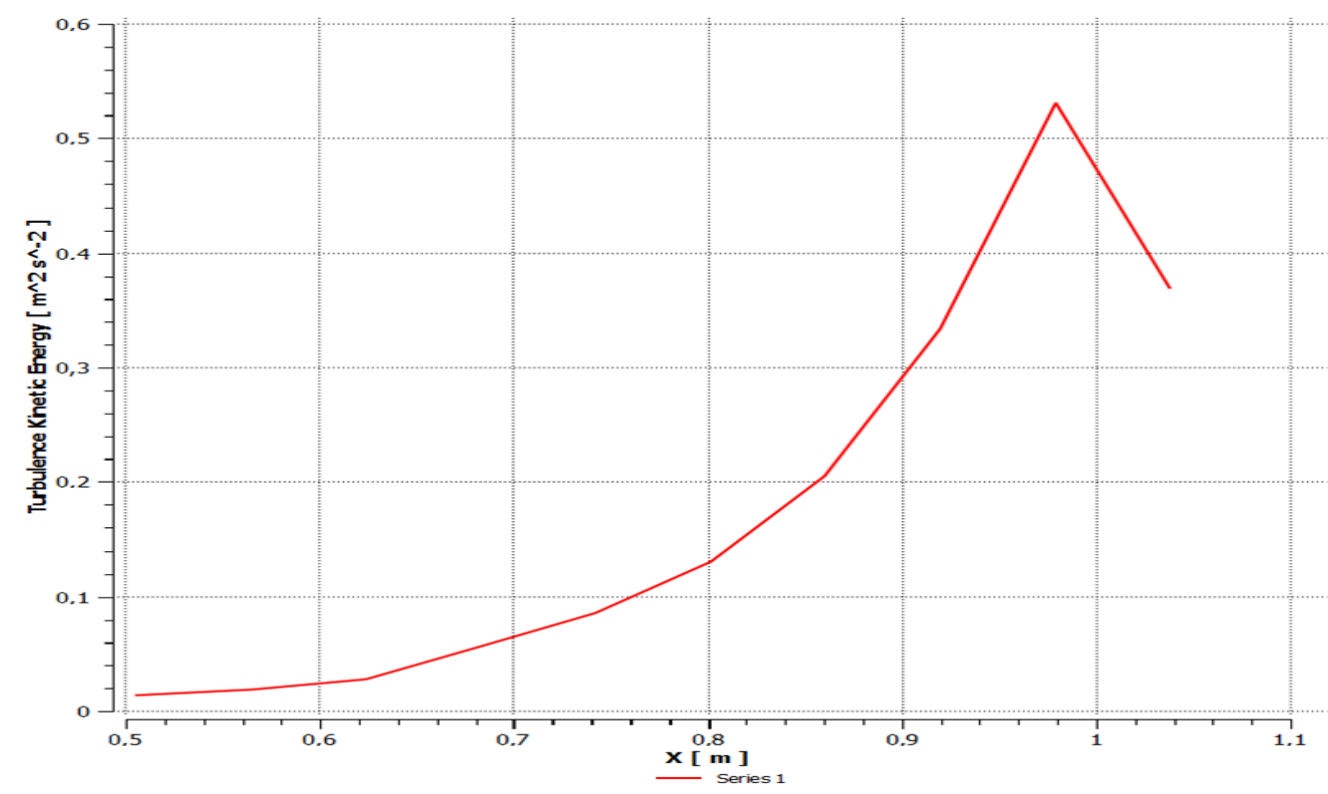




\section{CONCLUSION}

In order to evaluate applicability of the VOF method to the water-air circuit of CDTN, it was performed numerical simulations for full-scale air-water conditions using the parameters of Table 1 using ANSYS 18.

The results of the numerical simulations show that for a velocity of water of the $0.022 \mathrm{~m} / \mathrm{s}$ the same disturbances observed in the literature (Figure 1) start to appear at the interface as shown in Figure 9, that is, the same instabilities, hydraulic jump, and chaotic interface movement appearance during a CCFL experience are observed. However, for the parameters in Table 1, it was not observed deflooding.

The air-water countercurrent flow limitation was investigated in the geometry of the hot legs of PWRs. In this study, it was verified that the onset of flooding does not depend only on the dimensional characteristics of the test section but also on the injected water flow rate.

For the next works will be performed numerical simulations, using CFD, varying the parameters of Table 1 according to the experimental results obtained by Navarro in 2005 [2], and generate the flooding and deflooding curves.

\section{ACKNOWLEDGMENT}

This research project is supported by the following Brazilian institutions: Nuclear Technology Development Center (CDTN), Brazilian Nuclear Energy Commission (Cnen), Research Support Foundation of the State of Minas Gerais (Fapemig), Brazilian Council for Scientific and Technological Development (CNPq, program PEC-EG), Coordination for the Improvement of Higher Education Personnel (Capes), Federal Center for Technological Education Celso Suckow da Fonseca (Cefet), Eletrobrás Termonuclear S.A. (Eletronuclear), and National Institute for Innovative Nuclear Reactors (INCTRNI). 


\section{REFERENCES}

[1] Al Issa, S.; Macian, R. Experimental investigation of countercurrent flow limitation (CCFL) in a large-diameter hot-leg geometry: A detailed description of CCFL mechanisms, flow patterns and high-quality HSC imaging of the interfacial structure in a 1/3.9 scale of PWR geometry. Nucl. Eng. Des. V. 280, p. 550-563, 2014.

[2] Navarro, M.A. Study of countercurrent flow limitation in a horizontal pipe connected to an inclined one. Nucl. Eng. Des. V. 235, p. 1139-1148, 2005.

[3] Al Issa, S.; Macian, R. A review of CCFL phenomenon. Annals of Nuclear Energy. V. 38, p. 1795-1819, 2011.

[4] Chistophe V; et Al. Counter -current flow limitation in a model of the hot leg of a PWR - comparison between air/water and steam/water experiments. Nuc.Eng.Des. V. 245, p. 113-124, 2012.

[5] Deendarlianto; Thomas Hohne; Dirk Lucas; Karen Vierow; Gas-liquid countercurrent two-phase flow in a PWR hot leg: A comprehensive research review. Nuc. Eng.Des. V. 243, p. 214-233, 2011.

[6] Deendarliando; Chistophe Vallée; Dirk Lucas; Matthias Beyer; Heiko Pietruske; Helmar Carl. Erratum to "Experimental study on the air/water counter-current flow limitation in a model of the hot leg of a pressurized water reactor". Nuc. Eng. Des. V. 241, 2011 p. 3359-3372, 2011.

[7] Ohnuki, A. Experimental study of counter-current two-phase flow in horizontal tube connected to inclined riser. J. Nucl. Sci. Technol. V. 23, p. 219-232, 1986.

[8] Moukalled, F; Mangani, L; Darwish, M. The Finite Volume Method in Computational Fluid Dynamics. 2015.

[9] Chistophe, V; Hohne, T; Prasser, H.M; Suhnel, T. Experimental investigation and CFD simulation of horizontal stratified two-phase flow phenomena. Nuc. Eng. Des. V. 238, p.637-646, 2008.

[10] Ansys/Fluent. Volume of Fluid (VOF) Model Theory for Fluent. Available at: https://www.sharcnet.ca/Software/Fluent6/html/ug/node880.htm. Accessed in: May (2017). 
[11] Y. Utanohara; I. Kinoshita; I.M. Murase; D. Lucas; C. Vallée; A. Tomiyama. Numerical simulations for steam-water multi-phase flow simulation tests using the $1 / 3$ scale rectangular channel simulating a PWR hot leg. Nuc. Eng. Des. V. 249, p. 14-23, 2012. 